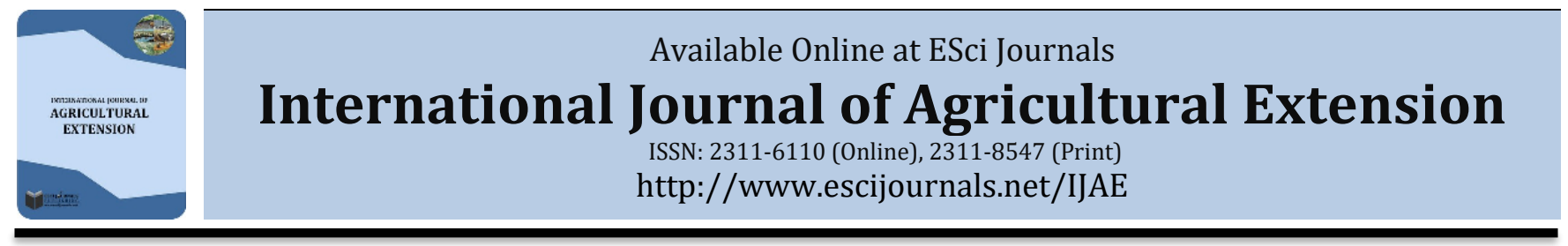

\title{
LARGE SCALE DEMO PLOT TRIAL PROJECT OF POTASH FERTILIZATION FOR INCREASED YIELD AND PROFITABILITY FOR SMALLHOLDER SOYBEAN FIELDS IN INDIA
}

\author{
aJoachim B. Nachmansohn, bPatricia Imas, cSurinder K. Bansal \\ ${ }^{a}$ Agricultural Fertilizer, Soil \& Water Management Expert, Yeruham, Israel. \\ ${ }^{b}$ ICL Fertilizers, Potash House, Beer Sheva, Israel. \\ c Potash Research Institute of India, Sector-19, Dundahera, Delhi-Gurgaon Road, Gurgaon, India.
}

\begin{abstract}
A B S T R A C T
Agriculture is the backbone of the Indian economy, in spite of concerned efforts towards industrialization in the last three decades. Therefore, the soil quality and fertility are the major factors in crop production. Declining soil fertility is one of the primary factors that directly affect crop productivity, and fertilizer-use is a key factor in order to keep soil fertility and productivity. A major factor in declining soil fertility is potassium (K) depletion, especially on smallholder farms where fertilization decisions are not based on regular soil testing. Most of the smallholder soybean producers do not have access and investment capacity to soil testing services. Therefore, there is a need to create $\mathrm{K}$ fertilizer recommendations based on empirically verified knowledge at India-specific scale. Such large-scale studies, in local filed conditions, are currently lacking. In order to bridge this gap, and generate proven set of directly applicable recommendations, a large-scale plot trial was launched; the Potash for Life (PFL) project. The study evaluated the K response in soybean when fertilizing with potash on $\mathrm{K}$ depleted soils in local variable field conditions. The aim was to (1) evaluate the effect and response consistency of K application on soybean yield, (2) to demonstrate to farmers the increased yield and profitability from K-inclusive fertilization regimes for this crop and give recommendations for transient yield increase, and (3) to raise the awareness among smallholder farmers about the importance of $\mathrm{K}$ fertilization. A comprehensive experiment was carried out in Madhya Pradesh (M.P.) and Maharashtra. The methodology was straight-forward; two identical plots side by side, with the only difference that one of them was fertilized with additional potash. The results showed a significant yield increase response from the potash application; the average yield increase was $244 \mathrm{~kg} \mathrm{ha}^{-1}$ or $26 \%$ in M.P., and $105 \mathrm{~kg} \mathrm{ha}^{-1}$ or $36 \%$ in Maharashtra. This entailed an average additional net profit of ₹ 6,681 INR ha-1 and ₹ 2,544 INR ha-1, in M.P. and Maharashtra respectively. It was concluded that the soil status of plant available $\mathrm{K}$ is significantly lower than the plant demand for soybean production in the two states, Consequently, $\mathrm{K}$ fertilization is necessary in order to improve agricultural practices and optimizing yields. Ultimately, following recommendations given in this study would allow farmers to generate additional profit, which could further allow them to invest in fine-tuning fertilizer practices through the means of soil testing.
\end{abstract}

Keywords: Soil-fertility, Potassium, Fertilizer, Yield increase, Fertilizer-use, Madhya Pradesh, Maharashtra.

\section{INTRODUCTION}

Agriculture is forming the backbone of the Indian economy in spite of concerned efforts towards industrialization in the last three decades. As such, agriculture contributes with $15 \%$ to the net domestic product in India (FAO, 2018). India's economy has experienced a remarkable progress during recent decades.

\footnotetext{
* Corresponding Author:

Email: consulting@joachimnachmansohn.com

(C) 2019 ESci Journals Publishing. All rights reserved.
}

In spite of that, $70 \%$ of the population still live in rural areas and are dependent on agriculture (FAO, 2018). The ever-increasing demand for food, feed, and fibers, and the limitation of arable land, necessitate not only the practices of preserving, managing, and enriching the natural resources, but also the up-scaling of land-use-efficiency. Soil forms the basis for any crop production activity and is the most precious natural resource. Declining soil fertility is one of the primary factors that directly affect crop productivity. Therefore, soil fertility management is 
crucial in order to ensure productivity and nutritional security, while maintaining soil health and sustainability (Prasad \& Power, 1997). Subsequently, fertilizer-use is a key factor in order to ensure soil fertility and productivity. Fertilizers are one of the costly inputs in agriculture. Still, if used correctly, it can be one of the most profitable (FAO, 2005). It's a fact that imbalanced and incorrect use of fertilizers not only afflicts nutrient use efficiency, but it also can cause deterioration in soil quality (Wallace, 2008). Therefore, a balanced fertilizer use must be promoted, as it's an absolutely necessary way to prevent both soil fertility decline, from too low use, or soil quality deterioration from over-use or imbalanced use.

Soybean is recognized as an important premier crop globally. It's a major source of vegetable oil, protein and animal feed. Due to the high protein and oil content, soybean is a very important food commodity all over the world. The soy protein is complete, as it contains all essential amino acids, and supplies them in sufficient amounts. For instance, soybean oil is the most widely consumed vegetable oil worldwide (FAO, 2004).

India is the fifth largest producer of soybean in the world, after USA, Brazil, Argentina and China. Soybean is one of the fastest growing crops in India. Soybean is grown as a Kharif crop in India. The top three soybean growing states are Madhya Pradesh, Maharashtra and Rajasthan and together they account for approximately $90 \%$ of the area in India under soybean cultivation (FAO, 2016). They are followed by Karnataka, Andhra Pradesh, Gujarat and Chhattisgarh (SOPA, 2018). Madhya Pradesh has around 40-50\% share in the total production in India, closely followed by Maharashtra. India produces approximately 12 million metric tons of soybean annually. There are about 120 soybean processing plants with an installed capacity of over 25 million tons (FAO, 2016). Such a huge production obviously has a deep impact on the society, livelihoods and national economy. M.P. stands out, not only for the highest production in the country, but the state also has global recognition, due to the fact that its majority of revenue and income comes from the soybean production.

The rate of smallholder-based soybean production increase in India is one of the most remarkable stories in recent agricultural history. Many farm communities where the crop has found a niche have had substantive improvements in income and quality of life (FAO, 2016). At the same time, the soy production and industry of the country are crippled by low yields, mostly rainfed production, limited domestic demand, inadequate irrigation, and poor infrastructure, and outdated fertilizer practices (Chand, 2007). The country needs to overcome these bottlenecks by doubling yields through different means, such as mechanized sowing and harvesting, improving market access for cultivators, improving irrigation in farms, and not the least, ensuring sufficient and balanced plant nutrient supply via correct and updated fertilizer practices.

The soybean was extensively studied due to its global importance, which lead to very comprehensive understanding of its demands and optimal growing conditions. Many studies in the past have shown the importance of potassium (K) in soybean production (Pettigrew, 2008; Yin \& Vyn, 2003; Bhangoo \& Albritton, 1972). However, it is well known that results from highly controlled studies do not necessarily translate into direct recommendations, especially in smallholder agriculture with sub-optimal practices overall, and relatively low investment capacity of the producers. In India, the practice of omitting $\mathrm{K}$ from the regular fertilization is common and has been a standard practice in the past few decades, especially in soils that are by definition classified as "K-rich soils". However, even K-rich soils can be depleted after years of intensive agricultural production. The body of research suggests just that, reporting the positive crop response to applied $\mathrm{K}$ in Vertisols in India, which are considered to be rich in K (Singh \& Wanjari, 2012; Dwivedi et al., 2007; Chen et al., 2000). Balanced and K-inclusive fertilizer regimes hold an important potential to contribute significantly to this end, and severely boost yield levels.

We identified the absence of large-scale field studies of soybean response to $\mathrm{K}$ on smallholder farms in India that can be used to give reasonable fertilizer recommendations to farmers without the access to soil testing services. It is of uttermost importance to take measures that increase yield and profitability for the smallholder farmers, as well as profitability for the soybean industry. o do just that, a large-scale "Potash for Life (PFL)" project on farms across top soybeanproducing states in India was initiated with an aim to generate empirically verified, India-specific recommendations that can be directly applied on smallholder farms. PFL is a collaborative project between Indian Potash Limited (IPL) and International Chemical Limited (ICL) Fertilizers. In other words, the study aims to raise the awareness of the importance of potash 
fertilization in soybean, through demo plot trials in collaboration with local farmers, in which the results and profitability can be clearly seen and disseminated to other soybean producers. Furthermore, the large scale aspect of the project, provides a very clear overview of the soil fertility trends, with regards to $\mathrm{K}$, regardless of local practices, which can serve as important verification of very site specific research of more mechanistic nature.

Objectives: The trials had three main objectives:

- Evaluate the large scale MOP response for soybean, with recommended fertilizer blends on $\mathrm{K}$ depleted soils, as well as the consistency of the response in variable field conditions at smallholder farms.

- To demonstrate to farmers, the increased yield and profitability obtained in soybean, as a result of applying MOP in addition to the conventional use of DAP, urea and manure, and give recommendations for transient yield increase.

- Raise the awareness among smallholder farmers about the importance of $\mathrm{K}$ fertilization in soybean production

\section{MATERIALS AND METHODS}

Experimental Setup: Verification trials for K response in soybean were conducted in India in the states of M.P. (129 plot trials) and Maharashtra (15 plot trials) due to their centrality to the nation's soybean production and its need to increase production efficiency, profitability and sustainability. The trials were conducted in the fields of different farmers in the states throughout five districts in total; Harda (9 plot trials), Mandsaur (47 plot trials), Ratlam (38 plot trials) and Ujjain (35 plot trials) in M.P., and Latur (15 plot trials) in Maharashtra.

Each farmer grew soybean, but in some cases, they grew other crops as well in a multi-cropping system. For soybean, there were two plots per farmer laying side by side, one for the treatment and one for the control, with a one-meter wide path between them. Plots within a state can be considered relatively similar, however, similarity cannot be assumed between them. In Maharashtra all plots were irrigated 1-3 times during the season, while in M.P., the practice of irrigation was only applied in the district of Harda, which only represented 9 out of the 129 plot trials in M.P. Regardless of these details in difference, the irrigation practices were always the same for both treatments. For each treatment in a demo plot trial, the plot size was the same; it was consistently 0.4 ha throughout the five districts of the two states. Different improved varieties of soybean recommended for the areas were used. All of the recommended agronomic practices were effectively followed.

Table 1. Fertilizer type and the dose applied to the two treatments in the soybean demo plot trials in Harda, Mandsaur, Ratlam and Ujjain districts in the state of Madhya Pradesh in India.

\begin{tabular}{lcccc}
\hline Fertilizer source & \multicolumn{2}{c}{ Harda district $\left(\mathrm{kg} \mathrm{ha}^{-1}\right)$} & \multicolumn{2}{c}{ Other districts $\left(\mathrm{kg} \mathrm{ha}^{-1}\right)$} \\
\cline { 2 - 5 } & Control & $+\mathrm{K}$ & Control & $+\mathrm{K}$ \\
\hline $\mathrm{N}$ (from urea+DAP) & 50 & 50 & 25 & 25 \\
$\mathrm{P}_{2} \mathrm{O}_{5}$ (from DAP) & 60 & 60 & 60 & 60 \\
$\mathrm{~K}_{2} \mathrm{O}$ (from MOP) & 0 & 40 & 0 & 75 \\
\hline
\end{tabular}

a the three districts of Mandsaur, Ratlam and Ujjain.

Table 2. Fertilizer type and the dose applied to the two treatments in the soybean demo plot trials in the Latur district in the state of Maharashtra in India.

\begin{tabular}{lcc}
\hline Fertilizer source & \multicolumn{2}{c}{ Treatment $\left(\mathrm{kg} \mathrm{ha}^{-1}\right)$} \\
\cline { 2 - 3 } & Control & $\mathrm{K}$ \\
\hline $\mathrm{N}$ (from urea + DAP) & 50 & 50 \\
$\mathrm{P}_{2} \mathrm{O}_{5}$ (from DAP) & 75 & 75 \\
$\mathrm{~K}_{2} \mathrm{O}$ (from MOP) & 0 & 50 \\
FYM $^{\mathrm{a}}$ & $1-3 \mathrm{t} \mathrm{ha}^{-1}$ & $1-3$ tha $^{-1}$
\end{tabular}

a FYM (Farm Yard Manure) was derived from different kinds of domesticated animals depending on location and production. While the does varied between the farms under study, the dose and procedure was the same between each treatment and control plot. 
Treatments: There were two treatments: 1) control, where the common fertilizer practice of urea, DAP and manure was applied, and: 2) ' $+\mathrm{K}$ treatment', where muriate of potash (MOP) was applied, in addition to the urea, DAP and manure fertilizers. Thus, the control and the treatment were identical on each location, except for the MOP input in the ' $+\mathrm{K}$ treatment'. However, the local fertilizer practices varied between the districts as well as the states: the fertilizer regime was more extensive in Maharashtra (Table 1) compared to that of M.P. (

Table 2), not only in terms of NPK-dosage, but also in that farm yard manure (FYM) was only utilized in the state of Maharashtra. The dose of FYM was not researchermanaged in this study and was based on the availability of manure and farmers' usual practices. This way, the present study is able to evaluate if MOP application is beneficial without optimization of manure application, and regardless of farmer's current manure practices.

Statistical analysis: The statistical analysis was performed using t-tests. Data analysis was conducted in one block for each state, comparing all 129 and 15 data points in M.P. and Maharashtra respectively, with pairwise t-tests (paired two samples for the mean), in order to compare control plots with ' $+\mathrm{K}$ treatment' plots. The dataset was very carefully trimmed, in that only one value was removed; an outlier with a negative response value. It was excluded on the basis, that it's very unlikely that the MOP-addition was the reason for the negative outcome. In addition, the data set was dissected according to districts and other factors, in order to elucidate sources of variation. When comparing these secondary factors, two kinds of tests were used depending on purpose:

- When comparing more than two groups or statistical populations, the one-way-ANOVA-test was used

- When comparing only two groups or statistical populations, another kind of t-test was used, as they had different sample sizes (two-sample assuming unequal variance). The assumption of different variance preceding the t-test was based on an F-test that implied different variances. In all tests the confidence level had an $\alpha=0.95$.

\section{RESULTS}

Absolute Yield Increase: Potassium, applied as MOP $(\mathrm{KCl})$ in addition to the common fertilization practices of urea, DAP, and manure, resulted in a significant increase in soybean yield.

With an average yield increase of $244 \mathrm{~kg} \mathrm{ha}^{-1}$ and $105 \mathrm{~kg}$ $\mathrm{ha}^{-1}$, and an average additional net profit of ₹ 6,681 INR ha $^{-1}$ and ₹ 2,544 INR ha-1, in M.P. and Maharashtra respectively, the benefits arising from MOP application to the soybean growers are clear. The average control yield was $948 \mathrm{~kg} \mathrm{ha}^{-1}$ and $403 \mathrm{~kg} \mathrm{ha}^{-1}$ in M.P. and Maharashtra, respectively (Table 3 ).

Table 3. Mean yield levels for control and $+K$ plots, as well as mean yield increase levels, for soybean harvested in 2014 - 2016, in the states of Madhya Pradesh (M.P.) and Maharashtra, both per district and per state in total.

\begin{tabular}{|c|c|c|c|c|c|c|c|}
\hline & \multicolumn{5}{|c|}{ <------------- Madhya Pradesh ---------------> } & \multicolumn{2}{|c|}{ Maharashtra } \\
\hline & M.P. as a whole & Harda & Mandsaur & Ratlam & Ujjain & Latur $^{\mathrm{a}}$ & (unit) \\
\hline Control & 948 & 1426 & 841 & 965 & 923 & 403 & $\left(\mathrm{~kg} \mathrm{ha}^{-1}\right)$ \\
\hline$+\mathrm{K}$ & 1188 & 1692 & 1058 & 1198 & 1210 & 299 & $\left(\mathrm{~kg} \mathrm{ha}^{-1}\right)$ \\
\hline Increase, absolute & 244 & 265 & 217 & 233 & 287 & 105 & $\left(\mathrm{~kg} \mathrm{ha}^{-1}\right)$ \\
\hline Increase, relative & 26.0 & 18.7 & 25.6 & 24.7 & 29.8 & 36.4 & $(\%)$ \\
\hline
\end{tabular}

a In the case of Maharashtra, the 'per state' and 'per district' is the same, as soybean was only produced in the one district of Latur of Maharashtra.

The difference between both the control yield levels, and the yield increase MOP-response levels, between the two states M.P. and Maharashtra, were statistically verified. All average values were found stable, which is indicated by a low standard error of the mean, and the proximity between the median and the mean (Figure 3 and 4) and are thus representative of the dataset (Figure 1 and 2). The K-response range in M.P., in which the yield increase response to the MOP application was distributed, roughly ranged from 0 to $700 \mathrm{~kg}$ ha- 1 . The same ra nge for Maharashtra was 90 to $130 \mathrm{~kg}$ ha-1. There was no statistically significant difference between the mean yield increase levels, for the different districts in M.P. Still, even though no statistical difference between the means could be established, there were some differences in the distributions. For the district of Harda, all data points for yield increase were clustered very closely around the state trial average. For the Mandsaur and Ratlam districts, 
the distributions were similar, both compared to each other and to the state as a whole.

For the district of Ujjain, the distribution was different; it both had the highest maximum response values, as well as the highest upper quartile, giving the district the highest mean and the highest response distribution. In both states, there were clear trends in the response pattern to the MOP application. In M.P. the yield increase was evenly distributed, almost linearly except for the highest $\mathrm{K}$ responses in the upper end of the distribution and increased from the lowest to the highest response value. The slope of this increase was moderate (Figure 1a), which is also illustrated by the proximity of the upper and lower quartile in the box plot diagram (Figure 1c). The two highest response values can be considered outliers, in the sense that they stood out from the response in general. However, there's nothing abnormal with the response in and of itself, and therefore it does not misrepresent the data.

For Maharashtra the distribution was different; it was uniform, with only a slight distribution slope (Figure 2a), which is also illustrated by the close proximity of the whole boxplot distribution to the average value, as well as the absence of outliers (Figure $2 b$ ).

There is no statistically significant difference in average yield increase response between the districts in M.P., however, as there are significant differences between the average control yield levels, the interaction between these two facts, clearly shows that the yield increase response was not dependent on the control yield level. In fact, as can be seen in Figure 3, the difference in yield levels between the districts can be considerable, and still, the average yield increase response is similar for all of them (Figure 4a). Maharashtra however, does not follow this pattern; as both its control yield and MOP-response were significantly lower. Furthermore, there was consistent close proximity between the mean and median response values, both state and district wise (Figure 4a).

Relative yield increase: In relative terms, the application of MOP added to the common fertilizer practice of urea, DAP and manure, gave rise to an average soybean yield increase of $26.0 \%$ and $36.4 \%$, in M.P. and Maharashtra respectively. This corresponded to an average benefit-cost ratio (B:C-ratio) of 6:1 and 3:1, in M.P. and Maharashtra respectively, in terms of local MOP input cost and net profit increase, based on local and up-to-date market prices of crop product. All average values were found stable, which is indicated by a low standard error of the mean, and the proximity between the median and the mean (Figure $4 \mathrm{~b}$ ), and are thus representative of the data set (Figure 1 and 2). The difference between the average yields increase Kresponse levels, between the two states of M.P. and Maharashtra, were statistically verified. However, no such statistically significant difference could be established between the districts in M.P.

The K-response range in M.P., in which the yield increase response to the MOP application was distributed, roughly ranged from 0 to $77 \%$. The same range for Maharashtra was 27 to $48 \%$. In both states, there were clear trends in the response pattern to the MOP application, and they followed the same pattern as for the absolute yield increase. In M.P. the yield increase was evenly distributed, almost linearly except for the highest $\mathrm{K}$ responses in the upper end of the distribution and increased from the lowest to the highest response value. Figure 1. Absolute (a) and relative (b) yield increase due to $\mathrm{K}$ application, presented in an ascending distribution among 129 demonstration plot trials in Madhya Pradesh harvested in 2014-2016 and dissected according to the four districts of Harda, Mandsaur, Ratlam and Ujjain by different colors. The corresponding statistical analyses (c and d) are presented as box plot diagrams, where the middle line represents the median, and the upper and lower box edges represent the 25th and the 75th percentiles respectively. The mean is signified by the $x-$ marker. The bars reach the maximum and minimum values, outliers excluded, which are signified by small colored circles. Each district, as well as the state as a whole, is represented by a specific color, specified in the color-legend. The slope of this increase was moderate (Figure 1b), which is also illustrated by the proximity of the upper and lower quartile in the box plot diagram (Figure 1d).

The two highest response values can be considered outliers, in the sense that they stood out from the response in general. However, there's nothing abnormal with the response in and of itself, and therefore it does not misrepresent the data. For Maharashtra the distribution was different; it was uniform, with only a slight distribution slope (Figure 2c), which is also illustrated by the close proximity of the whole boxplot distribution to the average value, as well as the absence of outliers (Figure 2d). 


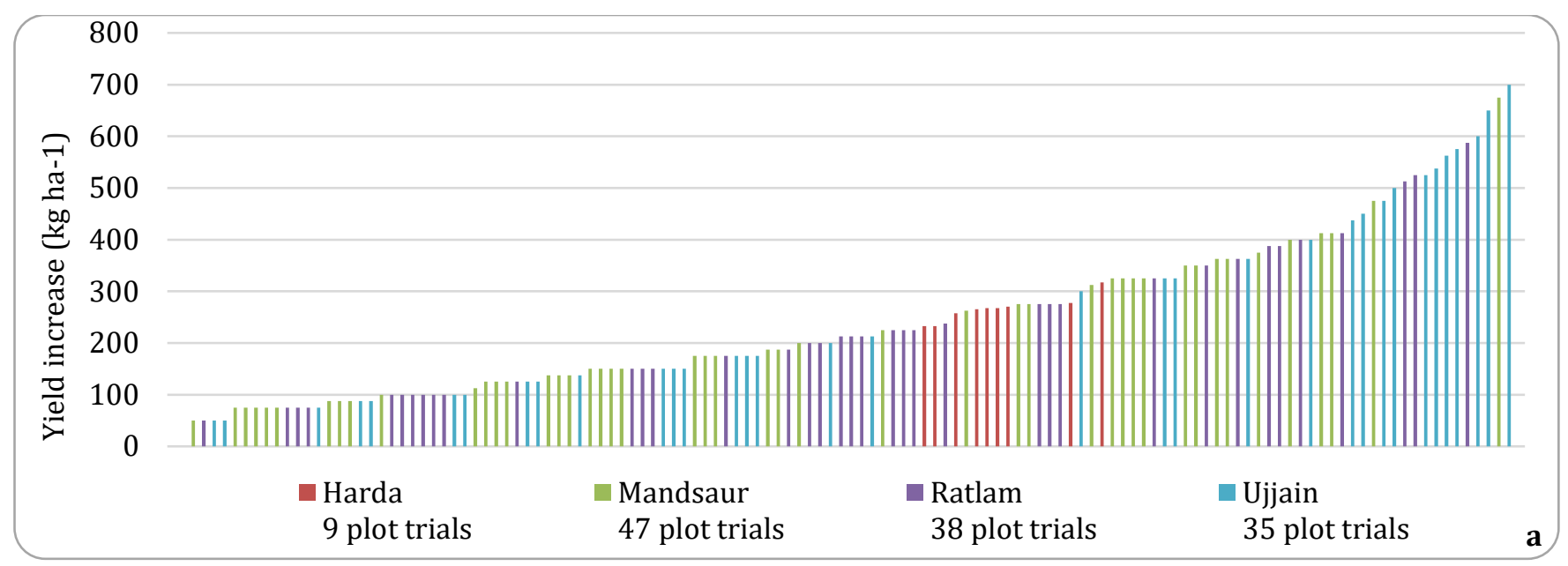

Figure 1(a). Absolute yield increases in Madhya Pradesh (129 plot trials).

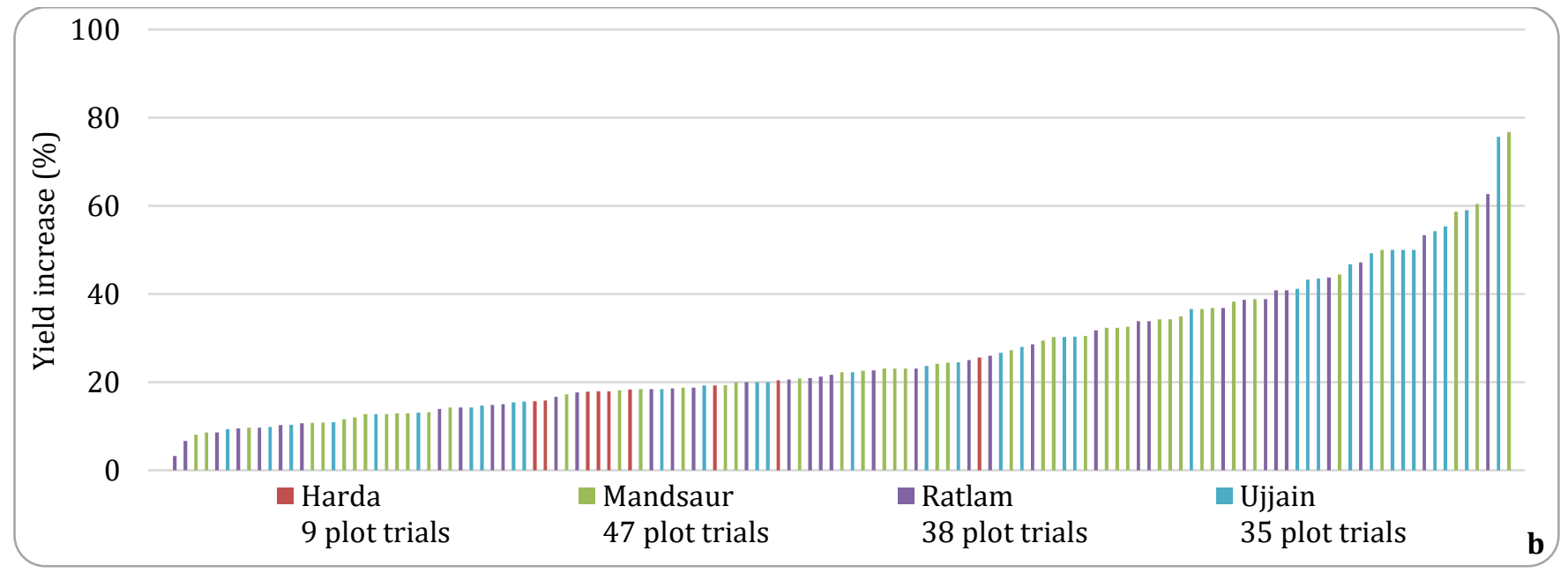

Figure 1(b). Relative yield increase in Madhya Pradesh (129 plot trials).
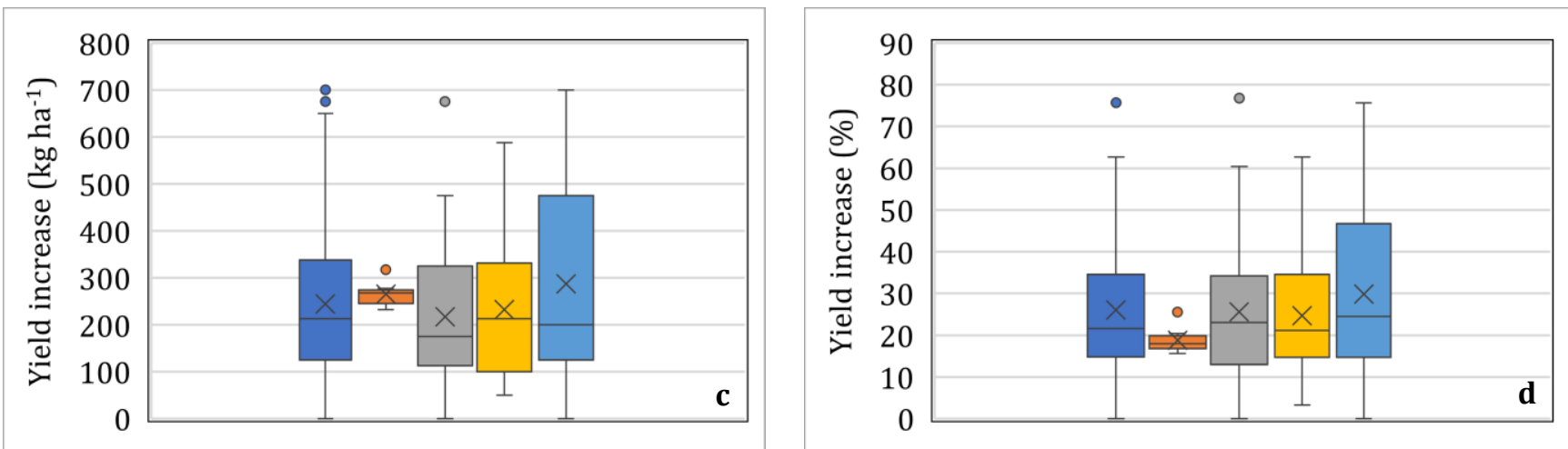

Madhya Pradesh
129 plot trials $\underset{9 \text { plot trials }}{\text { Harda }} \square_{47 \text { plot trials }}^{\text {Mandsaur }} \square_{38 \text { plot trials }}^{\text {Ratlam }} \square_{35 \text { plot trials }}^{\text {Ujjain }}$

Figure 1(c, d). Corresponding statistical analyses presented as box plot diagrams, where the middle line represents the median, and the upper and lower box edges represent the 25th and the 75th percentiles respectively. The mean is signified by the x-marker. The bars reach the maximum and minimum values, outliers excluded, which are signified by small colored circles. Each district, as well as the state as a whole is represented by a specific color, specified in the color-legend. 

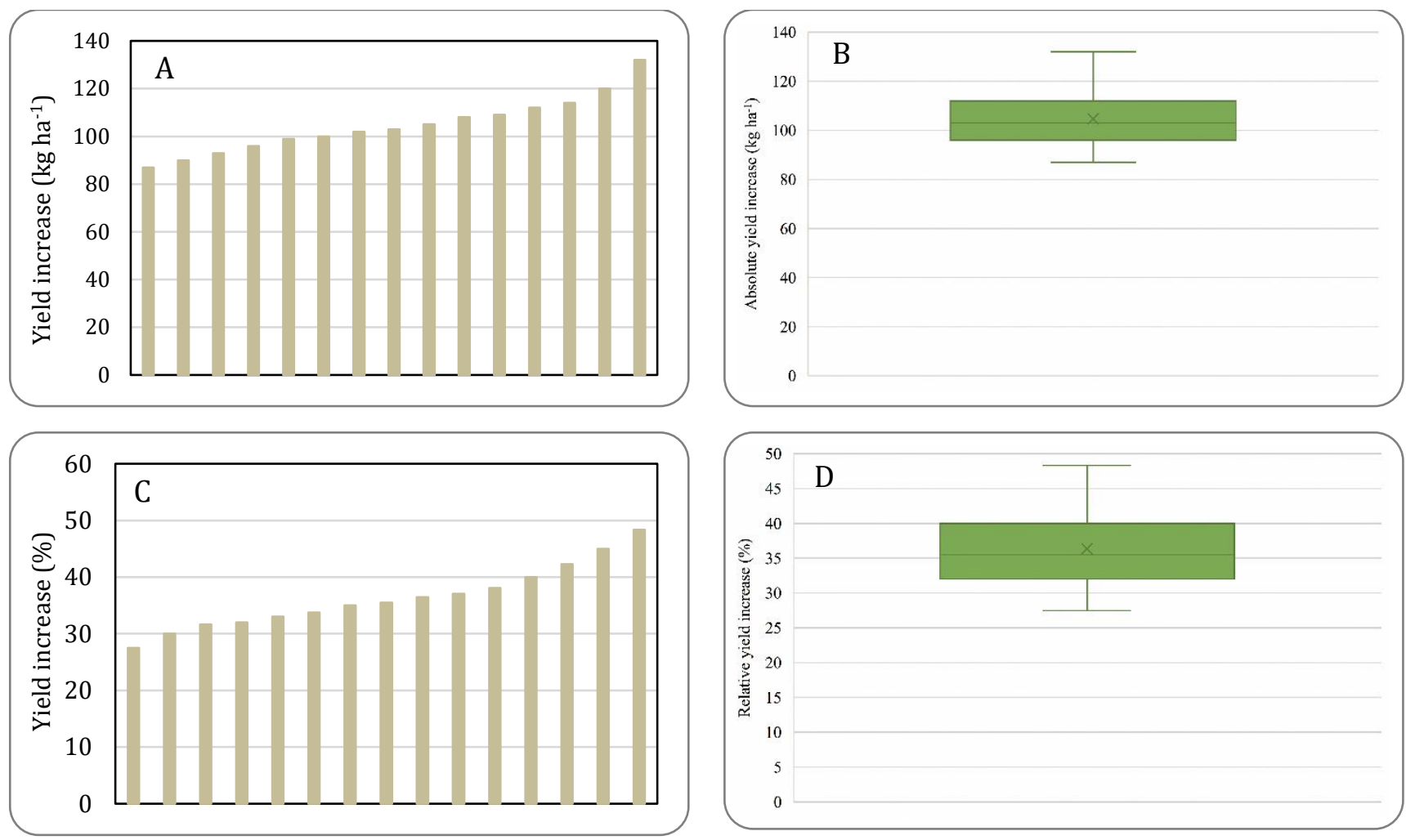

Figure 2. Absolute (a) and relative (c) yield increase due to $\mathrm{K}$ application, presented in an ascending distribution among 15 demonstration plot trials in Maharashtra, in the district of Latur, harvested in 2015. The corresponding statistical analyses ( $b$ and d) are presented as box plot diagrams, where the middle line represents the median, and the upper and lower box edges represent the $25^{\text {th }}$ and the $75^{\text {th }}$ percentiles respectively. The mean is signified by the $\mathrm{x}$-marker. The bars reach the maximum and minimum values.

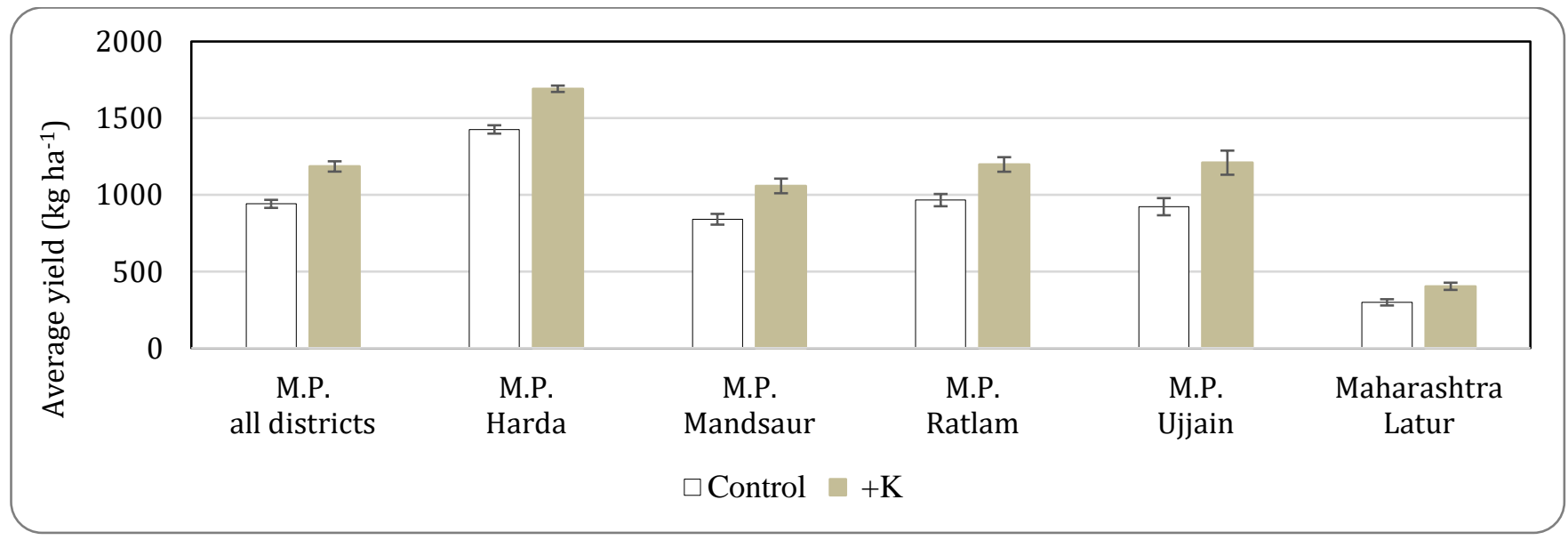

Figure 3. Mean soybean yield levels for control and K-applied plots, harvested in Madhya Pradesh (M.P.) 2014-2016, and harvested in Maharashtra in 2015. M.P. is illustrated both per district and for the state as a whole, while in Maharashtra there was only one district; Latur. 
Values represent all plot trials in each district or state. The error bars signify the standard error of the mean. Even though no statistically significant difference between the means between the districts of M.P. could be established, there were some differences in the distributions, and again they followed the same pattern as the absolute yield increase.

For the district of Harda, all data points for yield increase were clustered closely around the state trial average. For the Mandsaur and Ratlam districts, the distributions were similar, both compared to each other and to the state as a whole. For the district of Ujjain, the distribution was different; it both had the highest maximum response values, as well as the highest upper quartile, giving the district the highest mean and the highest response distribution.

\section{DISCUSSION}

The results of the plot trials are very clear and straightforward and speak for themselves. The additional MOP gave significant rise in yield levels that are both quantifiable and statistically verifiable. These results strongly imply that the soils in the experimental locations have undergone nutrient depletion and therefore lack plant available $\mathrm{K}$, which is in agreement with the available information in the literature (Hasan, 2002). The idea to disseminate MOP fertilization practices was thus shown to have a considerable potential to increase soybean productivity and profitability in both M.P. and Maharashtra.

The average yield increase levels are remarkably high for both states, certainly so in terms of relative yield increase. For M.P., its wide response range must as a whole be considered high; except for a few extreme values in both ends of the response range, the response was a yield increase of around $10 \%$ and $60 \%$, in the lower and upper end of the spectrum respectively. A yield increase of $10 \%$ is already a significant change, and a yield increase of 60 $\%$ is not only significant but remarkable (Figure 1). For Maharashtra, even the lowest MOP response was a remarkable $27.5 \%$ yield increase, 1.5 units above the average yield increase value in M.P. (Figure 2 and Table 3). Clearly, these results reveal the importance and potential of MOP-inclusive fertilizer regimes. The mean increases in this study were within the range of increases reported in the literature in studies (Yin \& Vyn, 2003; Ved et al., 2002; Bhangoo \& Albritton, 1972). Particularly high responses observed in this study are reported in the literature in experiments where $\mathrm{K}$ was applied to highly depleted soils (Ved et al., 2002). The variation in yield increase response was obvious in M.P. and moderate in Maharashtra, which isn't surprising considering the scope of the plot trial project, and the variability in location, control yield and local farmer practices in M.P. and the limited scope of the project in Maharashtra. The clear linear distribution trend of the yield increase response from MOP in M.P. suggests a moderate average natural variability of $\mathrm{K}$ depletion within the response range. The specifics of this trend provide evidence that the response patterns are due to the regional specific soil $\mathrm{K}$ status in M.P. In Maharashtra in which the MOP response was more uniform, the trend rather suggests an even and more severe $\mathrm{K}$ depletion. Regardless, the diversity in yields for both control and ' $+K$ treatment', requires a dissection before any final recommendations can be disseminated.

Differences between the districts: The difference in MOP-response between the districts can have several explanations, such as the difference in geography, practices and levels of $\mathrm{K}$ depletion. However, we know that neighboring districts, especially in M.P., is quite similar. At the same time, we know that there are different management factors between the districts that affect yield levels, such as irrigation, fertilizer regimes etc. Therefore, these factors need to be disseminated. However, in this context, it's interesting to note that the average control yield of $948 \pm 26 \mathrm{~kg}$ ha- 1 for the project in M.P., is well within the range of the annual state average (OGD, 2019). We can therefore conclude that the MOP-inclusive fertilizer regimes increased the yield levels to about one quarter $(26.0 \%)$ above the state average in M.P. For Maharashtra, it is more complex to determine the influence of the control yield in quantitative respect, as we have no other district in the state to compare with. However, as the state average for soybean yield levels was as high as 2200 ha $^{-1}$, and the control yield average in the plot trials in Maharashtra was only $403 \pm 20 \mathrm{~kg} \mathrm{ha}^{-1}$, it is safe to assume that the low control yield levels were at least one major governing factor in the comparatively low absolute MOP response $\left(+105 \mathrm{~kg} \mathrm{ha}^{-1}\right)$. Certainly so, as the relative yield increase response of MOP was exceptionally high; an increase of $36.4 \%$. We can therefore draw two tentative conclusions on the basis of findings: (1) the MOP input had a high effect, and (2) due to the low control yield level the absolute MOP-response remains quite moderate. Presumably, increased control yield levels would lead to 
higher MOP response in absolute terms. The most important question is why the yield levels in Latur were so low compared to the state average in Maharashtra.
This question will be explored below when disseminating the differences in management between the states.
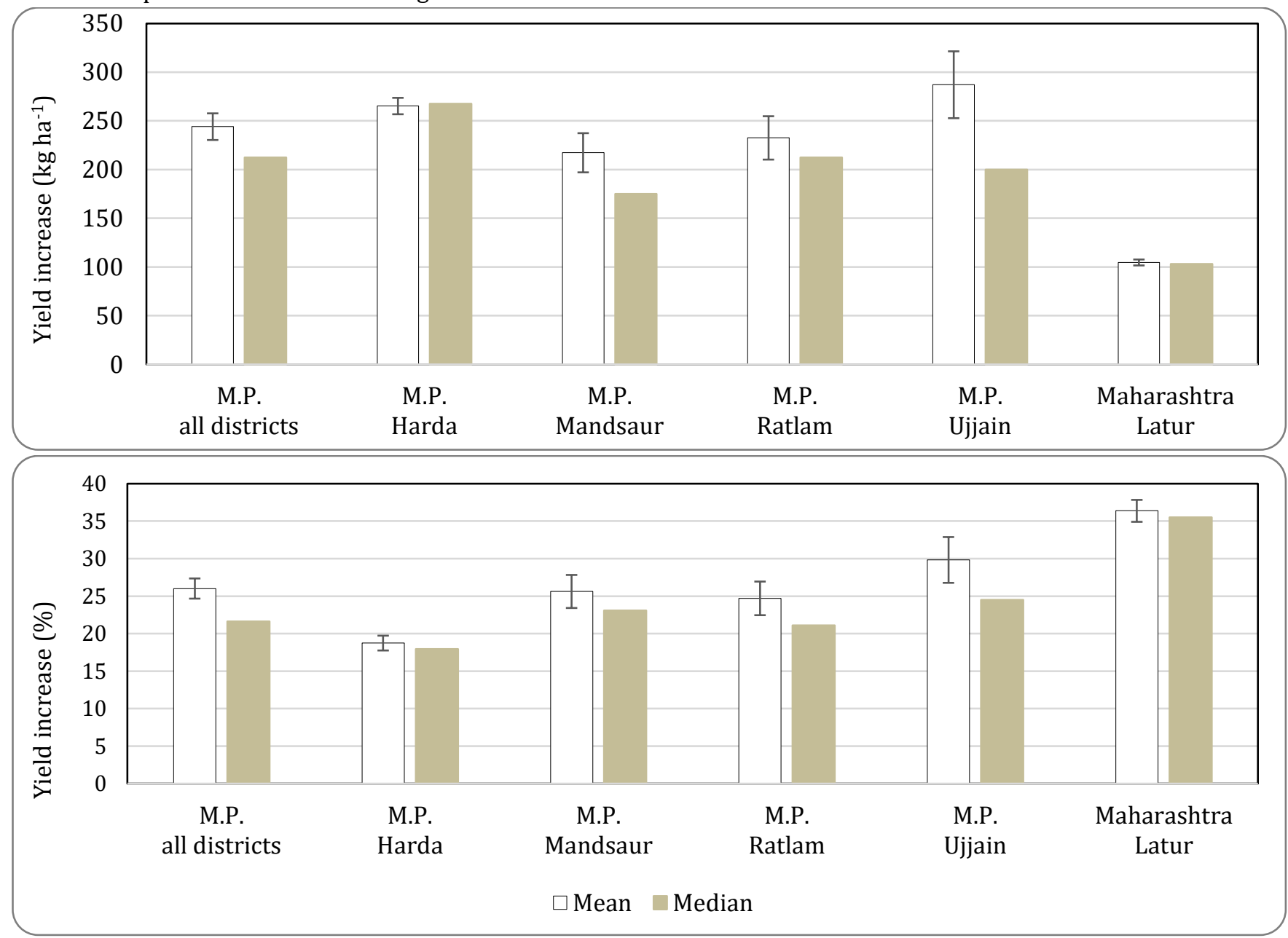

Figure 4. Absolute (a) and relative (b) average yield increase levels, illustrated both as mean and median, for soybean harvested in Madhya Pradesh (M.P.) 2014 - 2016, and in Maharashtra in 2015. M.P. is illustrated both per district and for the state as a whole, while in Maharashtra there was only one district; Latur. Values represent all plot trials in each district or state. The error bars signify the standard error of the mean.

Effects of different irrigation regimes: The districts had three different irrigation regimes:

- In Mandsaur, Ratlam and Ujjain (M.P.) there were no irrigation

- In Harda (M.P.) irrigation occurred once during the season

- In Latur (Maharashtra) irrigation occurred 1-3 times during the season

The expectation is that irrigation would increase the yield levels. This was found to be the case for Harda; in comparison to the other districts in M.P., the control yield level was significantly higher there. This indicates a yield- enhancing effect from the irrigation. However, the irrigation had no effect on the MOP response, as the district had the same response (statistically speaking) as the other districts in M.P.

For Latur in Maharashtra, the situation was different; even though irrigated up to three times, both control yield and MOP response levels were at the lowest in the whole project. This implies another major governing factor, as the irrigation seems to have increased yield levels in Harda. On the other hand, the irrigation might be a factor in levelling out the distribution of the yield levels in the districts, as Harda had the most uniform levels, followed by Latur. 
Effects of the different fertilizer regimes: Just as with irrigation, there were three slightly different fertilizer regimes for (1) Harda in M.P., (2) Mandsaur, Ratlam and Ujjain in M.P., and (3) Latur in Maharashtra (Table 1 \& Table 2). There are some indicators to the effects of different fertilizer regimes. In Harda, twice as much $\mathrm{N}$ was applied, compared to the other districts of M.P. It is likely that this is one factor behind the high control yield levels there. However, in Latur in Maharashtra, the $\mathrm{N}$ application was the same as in Harda, and the $\mathrm{P}$ application in Latur was the highest of all, in the soybean trials, and still had the lowest control yield levels. Two tentative conclusions can be drawn: (1) the higher fertilizer levels increases the likelihood of higher yield levels, and (2) the fertilizer regime is not the governing factor for the yield and response levels in Latur, Maharashtra.

Drought in Latur: Almost half of the plot pairs in Latur were reported to be drought affected. However, statistical analysis revealed that the plot pairs reported to be drought effected had higher yield levels both for control and ' $+\mathrm{K}$ treatment'. Of course, that makes no sense, as drought has a negative effect on yield levels. At the same time, we have consistently seen lower yield performance in Latur, inexplicable by the different management factors, such as irrigation and fertilizer practices. Therefore, the most reasonable conclusion is that all of Latur was severely drought affected; all of the district, as the response was uniform regardless of which plots were reported to be drought affected; and severely, as the yield levels, with or without MOP input, were far below the state average. Given these circumstances, it is impressive how much effect the MOP still had on yield levels; as stated above it caused an average yield increase of 36.4 $\%$. This further strengthens the conclusion that the soils in Latur, Maharashtra are K-depleted.

Regarding economics, due to the moderate response in absolute terms, the B:C-ratio in Latur was 3:1, only half of that in M.P. However, 3:1 is still a profitable venture, so if that is what can be expected during drought season, how much more cannot be expected during a season of average circumstances? Given the results in the neighboring state of M.P., a doubled B:C-ratio could be a reasonable expectation in Maharashtra in such case, as a rule of thumb.

Difference in distribution: Besides comparing averages, it's also important to disseminate the MOP response distributions for the districts, in order to establish what factors that governed the outcome. Why was the response range so wide in M.P. and so small in Maharashtra? It could partially be explained by the differences in management practices disseminated above. A reasonable inference is that variability in the outcome for both control and ' + K treatment' decreases with more irrigation and fertilizer inputs (MOP excepted). The largest response range is observed in the districts with the lowest irrigation and $\mathrm{N}$ and $\mathrm{P}$ input; Mandsaur, Ratlam and Ujjain. However, these are also the districts in which we see the highest MOP responses, significantly higher than the highest in the other districts. At the same time the MOP dosage was the highest in these districts. The most reasonable inference is therefore, that the natural variability in the soil $\mathrm{K}$ depletion in these districts is the main reason for the variation in the MOP response. This is further supported by the many data points in Mandsaur, Ratlam and Ujjain, both separately and combined, compared to Harda and Latur with only 9 and 15 plot pairs respectively.

Reasonable predictions and statistical inference: The statistical inference drawn from the data is that if a soybean farmer in M.P. would apply MOP according to the recommendations, he would likely make a yield increase of about 120 to $350 \mathrm{~kg}$ ha- 1 or $15-40 \%$. Given that the average B:C-ratio was $6: 1$, this implies a profitable outcome, even if the price for MOP and soybean would change significantly. For the drought affected Maharashtra, the corresponding figures would be between 30-40 \% and a B:C-ratio of 3:1, which implies a higher B:C-ratio during draught free seasons. Statistically, this is very convincing.

However, there is no way to predict crop response to $\mathrm{K}$ application at a given location with certainty, other than by conducting comprehensive soil and $\mathrm{K}$ crop response tests. A relevant approach can then be tailored accordingly and include a whole package of solutions. On the other hand, the consistently stable average values of soybean yield increase within predictable ranges, provide a high probability for most of the farmers to obtain significantly higher yields as a result of following the MOP application practices in these demo plot trials. This can make fine-tuning of fertilization regime on local field level cost effective in the future.

\section{CONCLUSIONS}

MOP application, in addition to commonly applied $\mathrm{N}$ and $P$ fertilizer, had an unequivocal effect, significantly increasing soybean yield in M.P. and Maharashtra. 
Importantly, the observed response was proven to be very consistent, despite the variations between the farms such as variations in manure practices.

The soil status of plant available $\mathrm{K}$ is significantly lower than plant demand in both states, in order to meet the need for soybean production, as indicated by clear and consistent response in crop yield. Therefore, the development of $\mathrm{K}$ inclusive fertilizer practices are necessary in order to improve agricultural practices and increase soybean yield and profit in M.P. and Maharashtra. In the short-term, the MOP doses successfully employed in this study should be recommended to the farmers in the states, as a transient mean to obtain higher yields and profits.

To finalize nutrient balances at the field scale, by means of comprehensive soil testing, would likely be economically unfeasible for local smallholding farmers. This study provides the farmers with a transient way of obtaining higher yields and profits without investments in soil testing. The results of this large-scale field trial empirically verify the need for K-inclusive fertilizer regime and demonstrate its benefits. Further, this study raised the awareness of importance of balanced fertilizer use and provides suggestions for MOP application rates which will gradually improve the existing practices within the farming system of local smallholders.

Improvements obtained by following recommendations from this study, while imperfect, are very significant economically. Applying the MOP dose used in this study would allow farmers to generate additional profit, which could further allow them to invest in fine-tuning fertilizer practices through the means of soil testing. This provides a clear and straight-forward path to productivity, profitability and economic sustainability, on a regional scale. Finally, the observed variation in the MOP response, give reason to investigate a higher MOP dose, as well as ways to fine-tune the recommendations on a local field scale. Therefore, further research which would include comprehensive soil testing is necessary to determine optimal MOP doses and application practices which ensure balanced crop nutrition, optimal fertilizer use, sufficient $\mathrm{K}$ availability whenever needed, and sustainable soil fertility.

\section{ACKNOWLEDGEMENT}

Indian Potash Limited and its regional officers and field staff are gratefully thanked for their active participation and kind help. Field staff of Project 'Potash for Life' and participating farmers are highly thanked for successfully conducting the demonstrations. Special thanks are due to ICL Fertilizers for extending financial assistance for the project. Grateful thanks are also to MD, IPL-Chairman PFL for all the support, kind advice and guidance in successful implementation of the project activities.

\section{REFERENCES}

Bhangoo, M.S., \& Albritton, D.J. (1972). Effect of Fertilizer Nitrogen, Phosphorus, and Potassium on Yield and Nutrient Content of Lee Soybeans 1. Agronomy Journal, 64(6), 743-746.

Chand, R. (2007). Agro-industries characterization and appraisal: soybeans in India. AGSF Working Document (FAO).

Chen, F., Lu, J.W. \& Wan, Y.F. (2000). Effect of Long-Term Potassium Application on Soil Potassium Content and Forms. Acta Pedologica Sinica 37(2), 233-241.

Dwivedi, A.K., Singh, M., Kauraw, D.L., Wanjari, R.H. \& Chauhan, S.S. (2007). Research Bulletin on 'Impact of fertilizer and manure use for three decades on crop productivity and sustainability, and soil quality under Soybean - Wheat System on Vertisol in Central India'. p.1-51.

Food and agriculture organization of the United Nations (FAO), (2016). Empirics of soybeans stocks in India: Trade perspective. [WWW document]. URLhttp://www.fao.org/fileadmin/templates/rap /files/meetings/2016/161109_AMIS_4.3Empirics_of_Soybeans_Stocks_in_India__Trade_Perspective.pdf(accessed 12.12.2018).

Food and agriculture organization of the United Nations (FAO), (2018). FAO in India.[WWW document]. URLhttp://www.fao.org/india/en/(accessed 04.01.2019).

Food and agriculture organization of the United Nations (FAO), (2005). Fertilizer use by crops in India. [WWW document]. URLhttp://www.fao.org/tempref/docrep/fao/00 9/a0257e/a0257e07.pdf(accessed 18.09.2018).

Food and agriculture organization of the United Nations (FAO), (2004). The role of soybean in fighting world hunger. [WWW document]. URLhttp://www.fao.org/3/a-bs958e.pdf(accessed 12.12.2018).

Food and agriculture organization of the United Nations (FAO), (2016). Empirics of soybeans stocks in India: Trade perspective. [WWW document]. URLhttp://www.fao.org/fileadmin/templates/rap /files/meetings/2016/161109_AMIS_4.3- 
Empirics_of_Soybeans_Stocks_in_India__Trade_Perspective.pdf(accessed 12.12.2018).

Food and agriculture organization of the United Nations (FAO), (2018). FAO in India. [WWW document]. URLhttp://www.fao.org/india/en/(accessed 04.01.2019).

Food and agriculture organization of the United Nations (FAO), (2005). Fertilizer use by crops in India. [WWW document]. URLhttp://www.fao.org/tempref/docrep/fao/00 9/a0257e/a0257e07.pdf(accessed 18.09.2018).

Food and agriculture organization of the United Nations (FAO), (2004). The role of soybean in fighting world hunger. [WWW document]. URLhttp://www.fao.org/3/a-bs958e.pdf(accessed 12.12.2018).

Hasan, R. (2002). Potassium status of soils in India. Better Crops Int, 16(2), 3-5. Chand, R. (2007). Agroindustries characterization and appraisal: soybeans in India. AGSF Working Document (FAO).

Open Government Data (OGD) platform India. (2019). District-wise, season-wise crop production statistics. Available online: https://data.gov.in/resources/district-wiseseason-wise-crop-production-statistics-1997 [Accessed 20/05/2019].

Pettigrew, W. T. (2008). Potassium influences on yield and quality production for maize, wheat, soybean and cotton. Physiologia plantarum, 133(4), 670681.

Prasad, R., Power, J. F. (1997). Soil Fertility Management for Sustainable Agriculture.CRC Press LLC, Boca Raton, Florida.
Prasad, R., Power, J. F. (1997). Soil Fertility Management for Sustainable Agriculture.CRC Press LLC, Boca Raton, Florida.

Singh, M., and Wanjari, R.H. (2012). Potassium responses and requirement of crops grown in Vertisols: Experiences from Long Term Fertilizer Experiment. Indian Journal of Fertilizers 8(3), 2632.

The Soybean Processors Association of India (SOPA), (2018). Soybean Production by State. [WWW document].

URLhttp://www.sopa.org/statistics/soybeanproduction-by-state/(accessed 12.12.2018).

The Soybean Processors Association of India (SOPA), (2018). Soybean Production by State. [WWW document].

URLhttp://www.sopa.org/statistics/soybeanproduction-by-state/(accessed 12.12.2018).

Ved, P., Kundu, S., Ghosh, B. N., Singh, R. D., Gupta, H. S., \& Prakash, V. (2002). Yield response of soybean (Glycine max) and wheat (Triticum aestivum) to potassium and changes of potassium status in soil after long-term sequential cropping (No. RESEARCH).

Wallace, A. (2008). Soil acidification from use of too much fertilizer. Com. Soil Sci. Plant Analysis. 25, 87-92.

Wallace, A. (2008). Soil acidification from use of too much fertilizer. Com. Soil Sci. Plant Analysis. 25, 87-92.

Yin, X., \& Vyn, T. J. (2003). Potassium placement effects on yield and seed composition of no-till soybean seeded in alternate row widths. Agronomy Journal, 95(1), 126-132. 